\title{
Paper An Optimized Propagation Model based on Measurement Data for Indoor Environments
}

\author{
Marco Morocho-Yaguana, Patricia Ludeña-González, Francisco Sandoval, \\ Betty Poma-Vélez, and Alexandra Erreyes-Dota \\ Department of Computer Science and Electronic, Universidad Técnica Particular de Loja, Loja, Ecuador
}

https://doi.org/10.26636/jtit.2018.117217

\begin{abstract}
Propagation is an essential factor ensuring good coverage of wireless communications systems. Propagation models are used to predict losses in the path between transmitter and receiver nodes. They are usually defined for general conditions. Therefore, their results are not always adapted to the behavior of real signals in a specific environment. The main goal of this work is to propose a new model adjusting the loss coefficients based on empirical data, which can be applied in an indoor university campus environment. The Oneslope, Log-distance and ITU models are described to provide a mathematical base. An extensive measurement campaign is performed based on a strict methodology considering different cases in typical indoor scenarios. New loss parameter values are defined to adjust the mathematical model to the behavior of real signals in the campus environment. The experimental results show that the model proposed offers an attenuation average error of $2.5 \%$ with respect to the losses measured. In addition, comparison of the proposed model with existing solutions shows that it decreases the average error significantly for all scenarios under evaluation.
\end{abstract}

Keywords-indoor, ITU model, log-distance model, loss measurement, one-slope model, path loss, propagation measurement, propagation models, radio propagation.

\section{Introduction}

Indoor environments are the most difficult scenarios in which communication systems operate, because the density of wireless communications is increasing on a daily basis, and the number of active devices is growing rapidly. Therefore, it is necessary to understand the nature of indoor propagation to predict the effects on electromagnetic signals through a propagation model.

The goal of propagation models is to determine the probability of successful operation of a communication system. It is an important factor in communication network planning. If the model is too conservative, the network could be very expensive. If it is too liberal, it can have low performance. Thus, fidelity of the model must be adapted to the network application [1]. It can be classified as a deterministic model, empiric model and as a combination of the two [2], depending on the environment characteristics available and their stability over time [3].

Since the indoor environment is more unfavorable than a typical outdoor scenario, determining a good propagation model is complicated, mainly due to the high variability in building structure and building materials [4]. Moreover, the propagation level can be radically affected by the interaction between obstacles, for instance, people motion or the closing of the doors. For this reason, the deterministic model is not usually used for indoor environments.

In the literature, there are many models providing for a number of parameters, for instance attenuation between floors [5] and optical phenomena, such as reflections [6]. Mathematical expressions are needed that model the specific indoor environmental conditions with more precision. Most models rely on the exponential law, with the propagation loss exponent depending on the frequency of operation [7], meaning that propagation is different for each frequency band.

Obtaining a mathematical model realistically reflecting the specific construction characteristics, such as type of building structure, shape of zones, wall thickness, type of materials used and separation distances between obstacles, is a complex task [8], [9]. For example, for $2.4 \mathrm{GHz}$ WLAN systems there are data for underground mines [10], space platforms [11] and airports [12]. Paper [13] compares different models in building offices, concluding that the standard deviation of the error between the estimation and measurement model is around $6 \mathrm{~dB}$. For the $914 \mathrm{MHz}$ band, article [14] presents a simple exponential model where the error in the loss calculus by a block of data is around $6 \mathrm{~dB}$ on average and, $9 \mathrm{~dB}$ in the worst case scenario. All these models are empirical.

In the literature, it is not easy to find empirical models based on extensive measurement campaigns, enabling losses to be determined and later adapted to a mathematical model, because it is an expensive and difficult task requiring high performance equipment and demanding that a strict methodology be followed [15], [16].

Among the most popular indoor empirical models is the One-slope model (OSM), which assumes a linear depen- 
dence between path losses (in $\mathrm{dB}$ ) and the logarithm of the distance between the transmitter and the receiver. It is a simple model, but is usually characterized by a high percentage of error because it does not take into account the environment characteristics in the calculus [17]. Another model is the Log-distance model [18] that is a combination of the modified power law and log-normal fading based on empirical data. Finally, the International Telecommunication Union (ITU) has a loss model resuming in recommendation P.1238 [19]. It is based on empirical construction coefficients obtained through a measurement campaign that calculates the losses per trip in five different types of offices for the frequency range from $900 \mathrm{MHz}$ to $100 \mathrm{GHz}$.

The goal of this paper is to propose a new model based on typical prediction models but with an adjustment of building campus environment parameters through an extensive measurement campaign, to obtain coefficients that are closer to real conditions.

This paper is organized as follows. Section 2 presents the indoor propagation models calculus and parameters. Section 3 describes the methodology for the measurement campaign and how the data is analyzed. In Section 4, the proposed model to calculate losses on the campus is described. The results are discussed in Section 5. Section 6 concludes the paper.

\section{Indoor Propagation Models}

In the indoor propagation environment, there are similar mechanisms (reflection, diffraction, and scattering) to those existing in outdoor environments. However, the indoor environment is considered more hostile [1]. For instance, inside a building, the signal levels can change by opening or closing a door [18].

Three key models, namely One-slope, Log-distance, and ITU indoor path loss models, are presented here.

\subsection{One-slope Model (OSM)}

In the One-slope indoor propagation model, a linear dependence between the path loss (PL) and the logarithm of the length $d$ of the path is assumed, as can be seen in Eq. (1):

$$
\mathrm{PL}[\mathrm{dB}]=\mathrm{PL}\left(d_{0}\right)+10 \cdot n_{\mathrm{OSM}} \log d,
$$

where PL $\left(d_{0}\right)$ represents the path loss at the reference distance equal to $1 \mathrm{~m}$ or Free-Space Path Loss (FSPL) for distance $d$ [1], and $n_{\mathrm{OSM}}$ is the loss exponent. It is evident

Table 1

One-slope model attenuation coefficient for indoor environments

\begin{tabular}{|l|c|}
\hline Environment (915 MHz) & $n_{\mathrm{OSM}}[\mathrm{dB}]$ \\
\hline Building (LOS) & 1.6 to 2 \\
\hline Building (NLOS) same floor & 2 to 4 \\
\hline Building (NLOS) through 1-3 floors & 4 to 6 \\
\hline
\end{tabular}

that OSM does not consider the random effects occurring in the propagation [20]. Table 1 presents the values of the attenuation coefficient when different environments at the frequency of $915 \mathrm{MHz}$ are considered.

\subsection{Log-distance Model}

It is a generic model frequently used in the literature to predict the propagation loss. It is logarithmically dependent on the distance, is used for a wide range of environments, and is expressed as:

$$
\mathrm{PL}[\mathrm{dB}]=\mathrm{PL}\left(d_{0}\right)+10 \cdot n_{\mathrm{LD}} \log \frac{d}{d_{0}}+X_{\sigma},
$$

where $\operatorname{PL}\left(d_{0}\right)$ is defined as in Subsection 2.1, $n_{\mathrm{LD}}$ denotes the path loss exponent, and $X_{\sigma}$ is a normal random variable with zero mean (in $\mathrm{dB}$ ) and standard deviation of $\sigma . X_{\sigma}$ includes in the model the shadowing effect and it is equal to zero in the case of no shadowing. Finally, Table 2 presents empirical values to path loss exponent and standard deviation for various indoor wave propagation cases [18].

Table 2

Path loss exponent and standard deviation for indoor environments

\begin{tabular}{|l|c|c|c|}
\hline \multicolumn{1}{|c|}{ Location } & $\begin{array}{c}\text { Frequency } \\
{[\mathrm{MHz}]}\end{array}$ & $\begin{array}{c}n_{\mathrm{LD}} \\
{[\mathrm{dB}]}\end{array}$ & $\begin{array}{c}\sigma \\
{[\mathrm{dB}]}\end{array}$ \\
\hline \hline Retails stores & 914 & 2.2 & 8.7 \\
\hline Grocery store & 914 & 1.8 & 5.2 \\
\hline Office, hard partition & 1500 & 3.0 & 7.0 \\
\hline Office, soft partition & 900 & 2.4 & 9.6 \\
\hline Office, soft partition & 1900 & 2.6 & 14.1 \\
\hline Textile/chemical & 1300 & 2.0 & 3.0 \\
\hline Textile/chemical & 4000 & 2.1 & 7.0 \\
\hline Paper/cereals (LOS) & 1300 & 1.8 & 6.0 \\
\hline Metalworking (LOS) & 1300 & 1.6 & 5.8 \\
\hline Metalworking (NLOS) & 1300 & 3.3 & 6.8 \\
\hline
\end{tabular}

Table 3

ITU attenuation coefficient for indoor environments

\begin{tabular}{|l|c|}
\hline Environment $(900 \mathrm{MHz})$ & $n_{\mathrm{ITU}}[\mathrm{dB}]$ \\
\hline \hline Open space & 20 \\
\hline Indoor propagation (office) & 33 \\
\hline Corridor & 18 \\
\hline Walls & 40 \\
\hline
\end{tabular}

\subsection{ITU-R (P.1238) Indoor Model}

The ITU model is a radio propagation model that predicts the indoor path loss inside a closed area, e.g. inside a building, and is given by [1]:

$$
\mathrm{PL}[\mathrm{dB}]=20 \cdot \log f+n_{\mathrm{ITU}} \cdot \log d+L_{f}(p)-28,
$$


where $f$ is the frequency in $\mathrm{MHz}, n_{\mathrm{ITU}}$ represents the distance power loss coefficient. The representative values for the attenuation coefficient for indoor environments are showed in Table 3 [19]. Additionally, in Eq. (3), $d$ is the distance in meters, $L_{f}(p)$ is the floor penetration loss factor, and $p$ denotes the number of floors between the transmitter and the receiver, in this case 0 .

\section{Methodology}

\subsection{Scenarios}

Two buildings were chosen on the Universidad Técnica Particular de Loja (UTPL), Loya, Equador, campus to allow examination of indoor propagation models in the presence of different cases. The two buildings are described below:

1. Building type A: It comprises four floors with office areas, movable partitions and wooden cubicle desks, meeting rooms and laboratories with different equipment (only on the fourth floor). The exterior walls are constructed with bricks and have wide windows. The corridors in this building have a minimum length of $14 \mathrm{~m}$ and a maximum length of $22 \mathrm{~m}$, and a minimum width between 1.76 and $7.65 \mathrm{~m}$ depending on the floor. In addition, in this building there are two types of doors: wooden doors (4 cm thick), and mixed doors (wood-glass) $(0.8 \mathrm{~cm}$ thick).

2. Building type B: It has five floors with classrooms and auditoriums. The measurements were only made on three floors of the building. The exterior walls are constructed with brick and metal structure. In this building the measurements were made in corridors, doors, and windows. The corridors on the first and second floors have dimensions of $40 \times 4.50 \mathrm{~m}$, and on the third floor $40 \times 3.20 \mathrm{~m}$. There are wooden doors that are $4 \mathrm{~cm}$ thick.

There are 9 measurements cases, divided in two situations: NLOS (Fig. 1) with obstacles (cases 1-7) and LOS (Fig. 2) with free space (cases $8-9)$. Obstacles 1 to 7 are wooden doors $(4 \mathrm{~cm})$, glass doors $(0.8 \mathrm{~cm})$, wooden-glass doors $(4 \mathrm{~cm})$, gypsum walls $(7.5 \mathrm{~cm})$, wooden walls covered with (a)

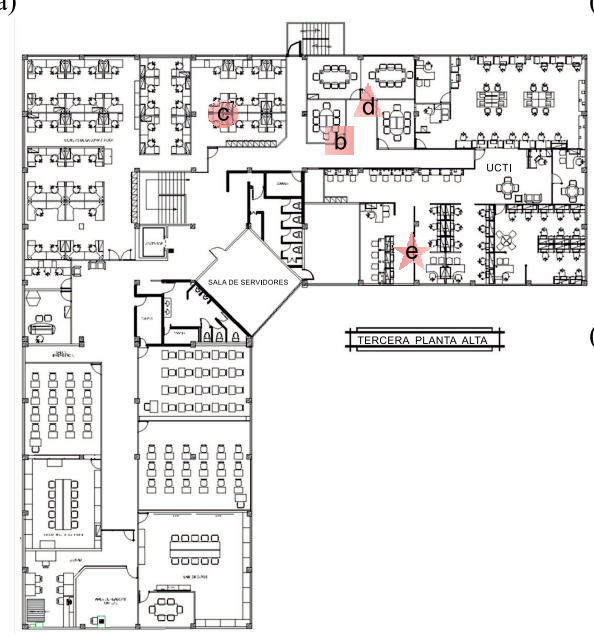

(b)

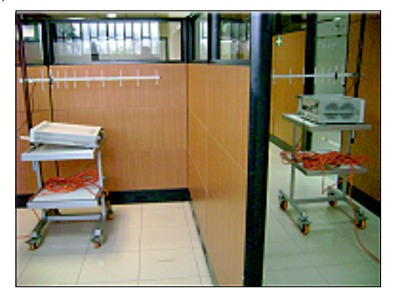

(d)

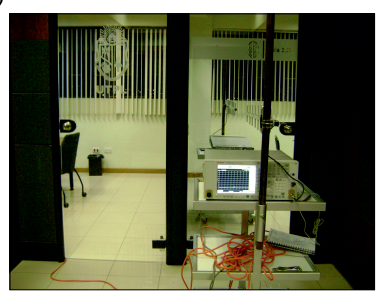

(c)

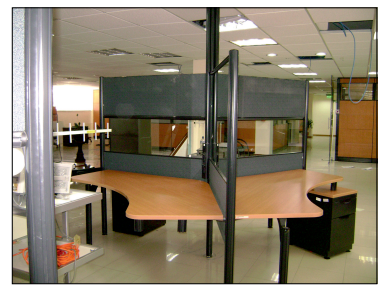

(e)

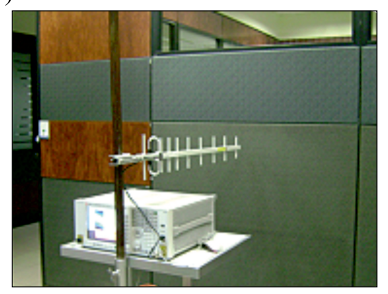

Fig. 1. NLOS type building: (a) architectural plan, (b) gypsum walls, (c) wood with glass and metal intersecting cubicles, (d) glass doors, and (e) wooden walls covered with textile and glass.

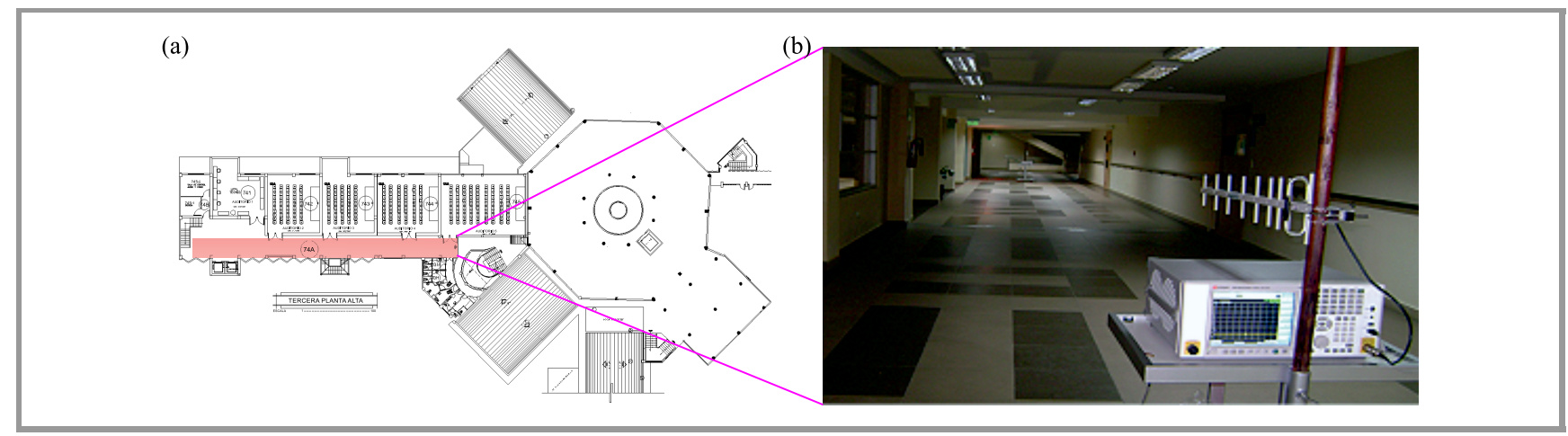

Fig. 2. LOS type building: (a) architectural plan and (b) corridors. 
textile and glass $(9 \mathrm{~cm})$, partitions (wood with metal joints) and wood with glass and metal intersecting cubicles $(9 \mathrm{~cm})$, respectively. The LOS situation is present in corridors: case 8 with the length of up to $22 \mathrm{~m}$, and case 9 with the length of over $22 \mathrm{~m}$.

\subsection{Equipment}

The measurement equipment consists of:

- Keysight ECE Vector Signal Generator N5172B-50, $9 \mathrm{kHz}-\mathrm{GHz}$ at the transmitter,

- Keysight Signal Analyzer N9000A-507, of $9 \mathrm{kHz}-$ $7.5 \mathrm{GHz}$ at the receiver,

- two antennas Yagi TG-Y915-14 that have the gain of $14 \mathrm{dBi}$ each one.

\subsection{Experimental Procedure}

Before starting the test, the transmitter and receiver antennas are positioned on metal supports at the height of $1.2 \mathrm{~m}$. The transmit power is adjusted to $-40 \mathrm{dBm}$ at $915 \mathrm{MHz}$, and the receiver is configured in the $900 \mathrm{MHz}$ band (902-928 MHz) with a central frequency of $915 \mathrm{MHz}$ (see Fig. 3).

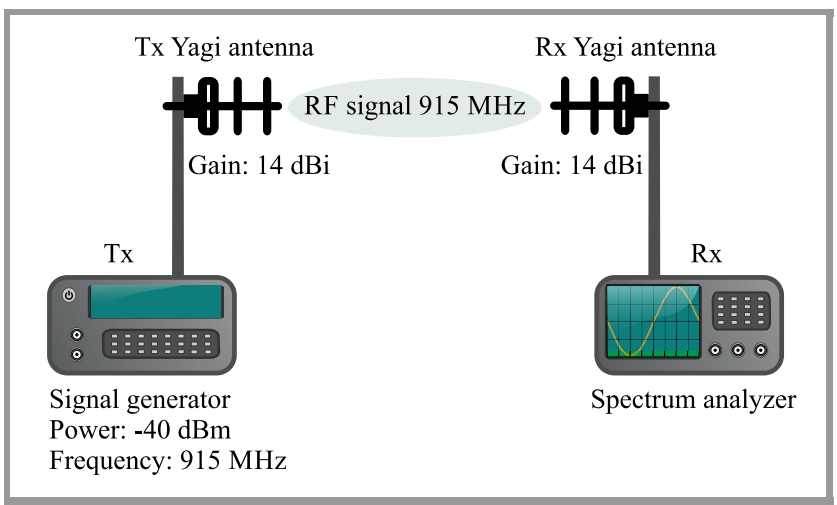

Fig. 3. Overview of the measurement setup.

The transmitter and the receiver are positioned at the distance corresponding to the case to be measured. Thus for the specific situation:

- NLOS doors, walls, separators, and cubicles - the transmitter and receiver are placed at an initial distance of $0.50 \mathrm{~m}$. Then, measurements are made by moving the transmitter in a straight line in $0.25 \mathrm{~m}$ steps (Fig. 4).

- LOS halls, and corridors - the transmitter and receiver are located at the same initial distance as in NLOS. Measurements are then taken every $0.5 \mathrm{~m}$, to the maximum value of $40 \mathrm{~m}$, like in Fig. 5.

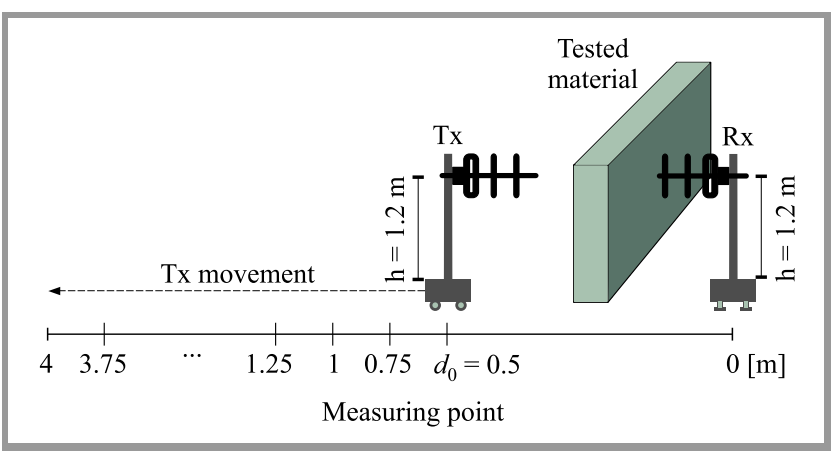

Fig. 4. NLOS measurement: doors, walls, partitions, and cubicles.

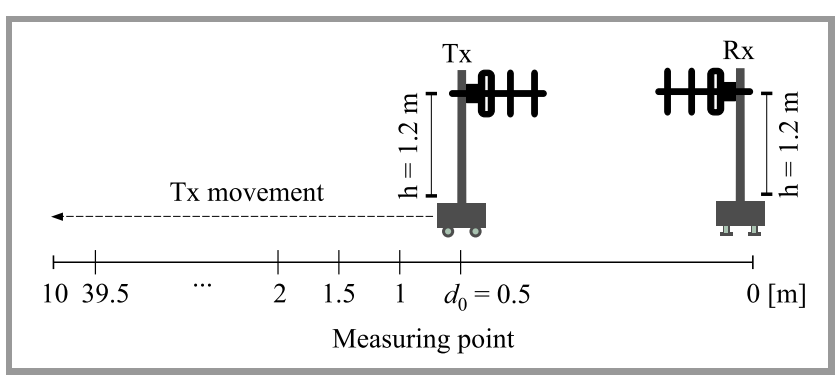

Fig. 5. LOS measurement: corridors.

\section{Proposed Model}

The objective of this work is to propose a model, with the specific coefficients used in loss prediction models adjusted to a university campus scenario, that can be used in similar environments.

As mentioned in previous sections, the typical models of propagation include the FSPL model, which calculates the loss that results from a line-of-sight path through free space and that depends on the square of the distance. Then, losses typical of a specific scenario are introduced through attenuation coefficients. Such models generally provide loss coefficients (different for each infrastructure) which, according to measurements that have been made at specific locations, are not feasible to use. For this reason, new loss coefficients must be obtained to have a model that is better adjusted to the actual behavior of indoor communications systems on a university campus.

Values obtained in the measurement campaign sere as baseline data for this task, as explained in Section 3. In order to obtain $n$, it clears this value from:

$$
L_{\text {total }}[\mathrm{dB}]=\mathrm{PL}\left(d_{0}\right)+n \cdot \log \frac{d}{d_{0}}+X_{\sigma},
$$

where PL is FSPL, $d$ is the distance and $L_{\text {total }}$ represents the path losses, which is calculated replacing the values in the load balance expression:

$$
P_{\mathrm{RX}}[\mathrm{dB}]=P_{\mathrm{TX}}+G_{A}-L_{\mathrm{total}},
$$

where $P_{\mathrm{RX}}$ is the reception power (obtained in the measurement campaign), $P_{\mathrm{TX}}$ is the transmission power and $G_{A}$ is the sum of antennas gain in transmission and reception. 
Then, with the measured values we calculate the standard deviation $(\sigma)$ and the correction factor $(\mathrm{CF})$. For each case, the standard deviation $\sigma$ is calculated with the variance $S$ of the measured average values through $\sigma^{2}=S$.

Table 4

Attenuation parameters for tested cases

\begin{tabular}{|c|l|c|c|c|}
\hline Case & \multicolumn{1}{|c|}{ Description } & $\begin{array}{c}\mathrm{CF} \\
{[\mathrm{dB}]}\end{array}$ & $\begin{array}{c}n \\
{[\mathrm{~dB}]}\end{array}$ & $\begin{array}{c}\sigma \\
{[\mathrm{dB}]}\end{array}$ \\
\hline \hline 1 & Wood doors & 42.23 & 10.55 & 0.97 \\
\hline 2 & Glass doors & 40.30 & 6.99 & 1.23 \\
\hline 3 & Mixed doors (wood-glass) & 41.31 & 9.81 & 0.73 \\
\hline 4 & Gypsum walls & 42.20 & 11.17 & 1.02 \\
\hline 5 & Textile-wood-glass walls & 41.79 & 8.54 & 1.39 \\
\hline 6 & Textile-wood-glass divisions & 44.06 & 9.73 & 2.86 \\
\hline 7 & Textile-wood-glass-metallic cubicles & 42.05 & 20.85 & 4.26 \\
\hline 8 & Short corridor $(<22 \mathrm{~m})$ & 41.76 & 9.91 & 2.52 \\
\hline 9 & Long corridor $(>22 \mathrm{~m})$ & 41.99 & 12.14 & 3.97 \\
\hline
\end{tabular}

Table 4 shows the attenuation coefficients and the respective standard deviation for different cases. Finally, the new coefficients are inserted in the defined model of Eq. (2), where $\operatorname{PL}\left(d_{0}\right)$ is replaced by CF according to the obtained measured values, so, the proposed model is resumed in Eq. (6):

$$
\mathrm{L}_{\text {total }}[\mathrm{dB}]=\mathrm{CF}+n \cdot \log d+X_{\sigma} .
$$

\section{Results}

In this section, a comparative analysis is presented, discussing results based on the average error. The average error is the relation between calculated attenuation and the measured attenuation.

Figure 6 depicts the measured attenuation versus calculated attenuation through the proposed model for cases 1 to 7 .

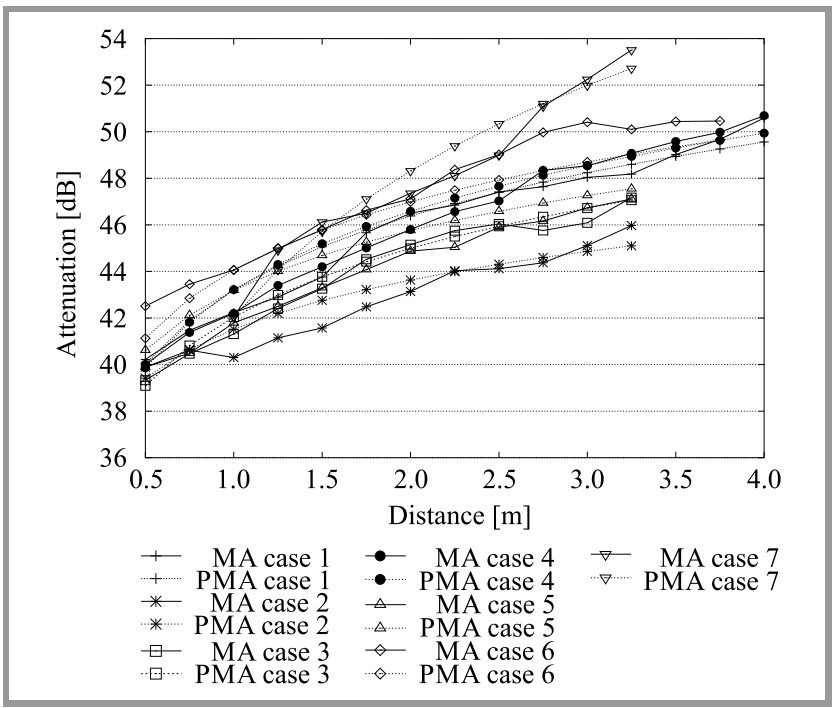

Fig. 6. Measured attenuation (MA) and proposed model attenuation (PMA) for obstacles (cases 1-7).
Every $25 \mathrm{~cm}$, wood, glass and mixed doors (corresponding to cases 1,2 and 3 ) increase the attenuation to $0.72,0.63$ and $0.85 \mathrm{~dB}$, respectively. The curves indicate clearly that glass doors represent the lower attenuation for the set of obstacles. The average error for them equals $0.46,0.56$ and $0.36 \mathrm{~dB}$ respectively. In addition, the results for cases 4 (gypsum walls) and 5 (wood walls) are showed; the average error is $0.54 \mathrm{~dB}$ and $1.03 \mathrm{~dB}$, respectively. The attenuation for case 6 is around $0.87 \mathrm{~dB}$ for each $25 \mathrm{~cm}$ and the error is $0.76 \mathrm{~dB}$. With cubicles (case 7) present in the area, the highest fluctuation rate is registered, and the average error equals $0.66 \mathrm{~dB}$.

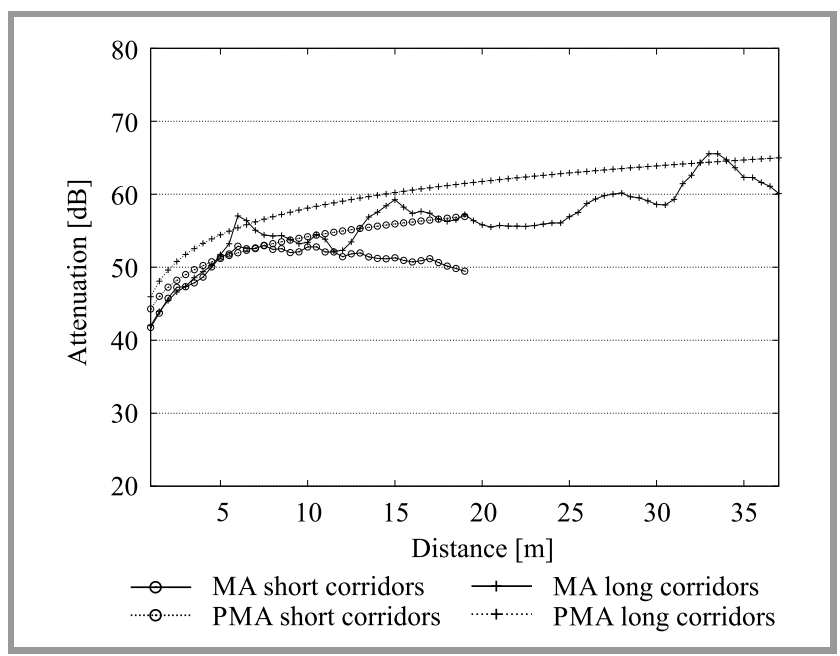

Fig. 7. Measured attenuation (MA) and proposed model attenuation (PMA) for cases 8 and 9.

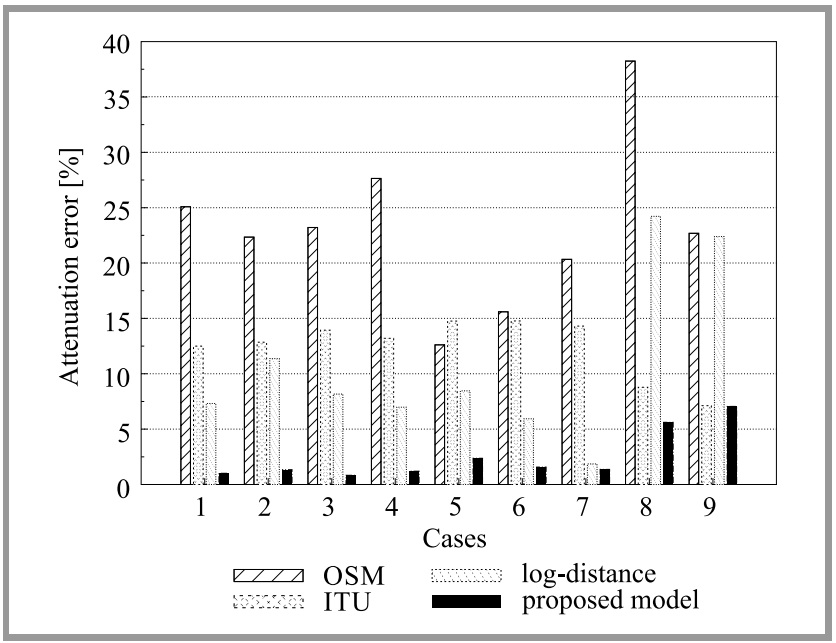

Fig. 8. Theoretical models versus proposed model attenuation error for indoor environments.

The attenuation for cases 8 and 9 is depicted in Fig. 7. The measured values show that the attenuation in short corridors is lower than in long corridors, with the variation of around $3 \mathrm{~dB}$ and peaks up to $7.96 \mathrm{~dB}$. The error is $2.83 \mathrm{~dB}$ and $3.9 \mathrm{~dB}$, respectively. Abrupt changes in attenuation curves are mainly due to the multipath effect caused by the variability of the indoor environment. 
Figure 8 shows the average error for the theoretical models and the proposed model. For cases 1 to 7 , the optimized model has lower average percentages of error of attenuation (smaller than 3\%) in relation to OSM, ITU and Logdistance models, whose average values equal $21.0 \%, 13.8 \%$ and $7.2 \%$, respectively, versus $1.4 \%$ of the proposed model. Moreover, for cases 8 and 9, OSM has an error of $30.5 \%$, ITU model error is $8.0 \%$ and Log-distance error is $23.3 \%$ versus $6.3 \%$ of the proposed model.

Among the mathematical models, the worst model that predicts the losses is the OSM with the error greater than $25 \%$, versus Log-distance model values of around $7.5 \%$. The Log-normal model has the lowest error percentage. It presents a better behavior for case 7 with $0.47 \%$, compared to the optimized model. But for cases 8 and 9 , ITU is a better adjusted model. For example, for case 9, the error is $0.07 \%$ for the proposed model. Nevertheless, ITU presents a measured attenuation variability of up to $11.59 \mathrm{~dB}$, versus $6.79 \mathrm{~dB}$ of the proposed model.

\section{Conclusions}

In this paper, some typical propagation models have been analyzed. An extensive measurement campaign was performed based on a strict methodology. With these results a new model was proposed. The proposed model specifies coefficients ( $n$ and $\sigma$ ) for structures, shapes, materials, and obstacles typical of a campus environment.

All approaches were have been analyzed, compared and the results are discussed. Theoretical models have a high error percentage - mainly the One-slope model with values between $12 \%$ and $27 \%$. Log-distance and ITU models have a better performance for the scenarios under study, with different obstacles and corridors considered. The proposed model decreases the attenuation error by approximately $10 \mathrm{~dB}$, meaning that the models analyzed have been optimized. Low error percentages are obtained in all scenarios. The proposed model presents the average measured attenuation data error of $2.5 \%$.

\section{References}

[1] J. S. Seybold, Introduction to RF Propagation. Wiley, 2005.

[2] U. Naik and V. N. Bapat, "Adaptive empirical path loss prediction models for indoor WLAN", Wirel. Personal Commun., vol. 79, no. 2, pp. 1003-1016, 2014 (doi: 10.1007/s11277-014-1914-9).

[3] I. Dey, G. G. Messier, and S. Magierowski, "Joint fading and shadowing model for large office indoor WLAN environments", IEEE Trans. on Antennas and Propag., vol. 62, no. 4, pp. 2209-2222, 2014 (doi: 10.1109/TAP.2014.2299818).

[4] J. H. Jung, J. Lee, J. H. Lee, Y. H. Kim, and S. C. Kim, "Raytracing-aided modeling of user-shadowing effects in indoor wireless channels", IEEE Trans. on Antennas and Propag., vol. 62, no. 6, pp. 3412-3416, 2014 (doi: 10.1109/TAP.2014.2313637).

[5] M. Sasaki et al., "Path loss characteristics between different floors from 0.8 to $37 \mathrm{GHz}$ in indoor office environments", in Proc. 21st Int. Symp. on Antennas and Propag. ISAP 2016, Ginowan, Okinawa, Japan, 2016.

[6] N. G. Fernández, "Modelo de Cobertura en Redes Inalámbricas Basado en Radiosidad por Refinamiento Progresivo", Doctoral Thesis, Universidad de Oviedo, Spain, 2006 (in Spanish).

[7] A. Samuylov, D. Moltchanov, Y. Gaidamaka, V. Begishev, R. Kovalchukov, P. Abaev, and S. Shorgin, "SIR analysis in squareshaped indoor premises", in Proc. 30th Eur. Conf. on Modelling and Simul. ECMS 2016, Regensburg, Germany, 2016, pp. 692-697 (doi: 10.7148/2016-0692).

[8] I. Rodriguez, H. C. Nguyen, N. T. Jorgensen, T. B. Sorensen, and P. Mogensen, "Radio propagation into modern buildings: Attenuation measurements in the range from $800 \mathrm{MHz}$ to $18 \mathrm{GHz}$ ", in Proc. 80th Veh. Technol. Conf. VTC Fall 2014, Vancouver, DC, Canada, 2014, pp. 1-5 (doi: 10.1109/VTCFall.2014.6966147).

[9] O. Felekoglu, "Propagation and performance analysis for a $915 \mathrm{MHz}$ wireless IR image transfer system", Ph.D. dissertation, Naval Postgraduate School, Monterey CA, USA, 2005 [Online]. Available: http://hdl.handle.net/10945/2155

[10] C. Nerguizian, C. L. Despins, S. Affès, and M. Djadel, "Radiochannel characterization of an underground mine at $2.4 \mathrm{GHz}$ ", IEEE Trans. on Wirel. Commun., vol. 4, no. 5, pp. 2441-2453, 2005 (doi: 10.1109/TWC.2005.853899).

[11] O. Fernandez, M. Domingo, and R. P. Torres, "Experimental Analysis of wireless data transmission systems in space platforms", IEEE Antennas and Propag. Mag., vol. 46, no. 4, pp. 38-60, 2004 (doi: 10.1109/MAP.2004.1373998).

[12] T. Chrysikos, G. Georgopoulos, S. Kotsopoulos, and D. Zevgolis, "Site-specific validation of indoor RF models for commercial propagation topologies at $2.4 \mathrm{GHz}$ ", in Proc. 7th Int. Symp. on Wirel. Commun. Syst. ISWCS 2010, York, United Kingdom, 2010, pp. 681-685 (doi: 10.1109/ISWCS.2010.5624276).

[13] F. Capulli, C. Monti, M. Vari, and F. Mazzenga, "Path Loss Models for IEEE 802.11 a Wireless Local Area Networks", in Proc. 3rd Int. Symp. on Wirel. Commun. Syst. . ISWCS 2006, Valecia, Spain, 2006, pp. 621-624 (doi: 10.1109/ISWCS.2006.4362375).

[14] S. Y. Seidel and T. S. Rappaport, "914 MHz path loss prediction models for indoor wireless communications in multifloored buildings", IEEE Trans. on Antennas and Propag., vol. 40, no. 2, pp. 207-217, 1992 (doi: 10.1109/8.127405).

[15] T. S. Rappaport, G. R. MacCartney, M. K. Samimi, and S. Sun, "Wideband millimeter-wave propagation measurements and channel models for future wireless communication system design", IEEE Trans. on Commun., vol. 63, no. 9, pp. 3029-3056, 2015 (doi: 10.1109/TCOMM.2015.2434384).

[16] M. Tolstrup, Indoor Radio Planning: A Practical Guide for 2G, $3 G$ and 4G. Wiley, 2015.

[17] A. Hrovat, G. Kandus, and T. Javornik, "A survey of radio propagation modeling for tunnels", IEEE Commun. Surveys Tutor., vol. 16, no. 2, pp. 658-669, 2014 (doi: 10.1109/SURV.2013.091213.00175).

[18] T. S. Rappaport, Wireless Communications - Principles and Practice. Upper Saddle River, NJ, USA: Prentice Hall PTR, 2002.

[19] ITU-T Recommendation P.1238-9, "Propagation Data and Prediction Methods for the Planning of Indoor Radiocommunication Systems and Radio Local Area Networks in the Frequency Range $300 \mathrm{MHz}$ to $100 \mathrm{GHz}$ ", ITU, Geneva, July 2017 [Online]. Available: http://www.itu.int/rec/RREC-P.1238/eu

[20] C. Monti, A. Saitto, and D. Valletta, "Indoor radio channel models for IEEE 802.15.4 technology", in Proc. 2nd Int. EURASIP Worksh. on RFID Technol. RFID 2008, Budapest, Hungary, 2008.

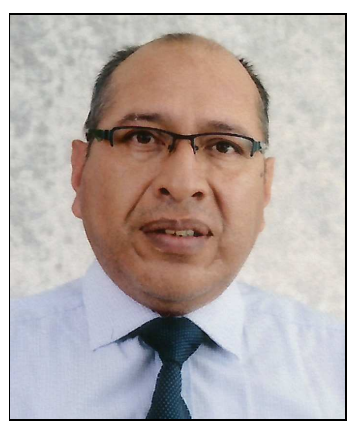

2/2018
Marco Morocho-Yaguana received his M.Sc. in Engineering from the Moscow Technical University of Communications and Informatics. He is a professor at the Computer Science and Electronics Department (DCCE) and Coordinator for the engineering degrees in electronics and telecommuni- 
cations at Universidad Técnica Particular de Loja since 2016. His research interests focus on the wave propagation, antennas and electromagnetism.

E-mail: mvmorocho@utpl.edu.ec

Department of Computer Science and Electronic

Universidad Técnica Particular de Loja

C/. Marcelino Champagnat S/N

1101608 Loja, Ecuador

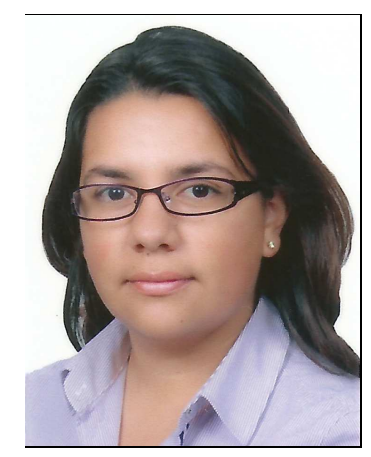

Patricia Ludeña-González received her B.Sc. degree in Electronic and Telecommunications Engineering from Universidad Técnica Particular de Loja (UTPL) in 2005. She has an M.Sc. in Telecommunications Networks since 2011 from the Rey Juan Carlos University in Spain. She is a Ph.D. Candidate at Universidad Politécnica de Madrid in Spain. She is a professor at the Computer Science and Electronics Department (DCCE) in UTPL since 2005. Her research interests focus on the optimization of protocols, traffic engineering, wave propagation in wireless telecommunications and new technology networks in rural wireless networks deployments.

E-mail: pjludena@utpl.edu.ec

Department of Computer Science and Electronic

Universidad Técnica Particular de Loja

C/. Marcelino Champagnat S/N

1101608 Loja, Ecuador

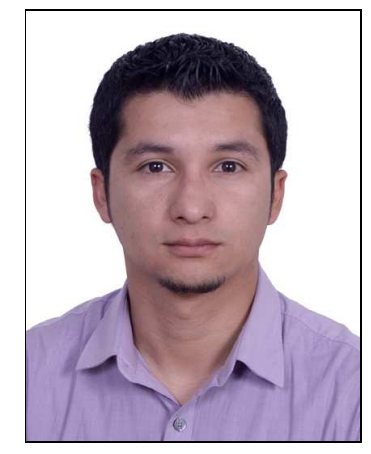

Francisco Alberto Sandoval Noreña received his B.Sc. degree in Electronics and Telecommunications Engineering from Universidad Técnica Particular de Loja (UTPL), and an M.Sc. degree in Electrical Engineering from the Pontifícia Universidade Católica do Rio de Janeiro (PUC-RIO), in 2008, and 2013, respectively. $\mathrm{He}$ is currently pursuing a Ph.D. degree in Electrical Engineering with École de Technologie Supérieure (Uni- versity of Quebec), Canada. He has worked, since October 2008, at UTPL as an auxiliary professor at the Computer Science and Electronics Department (DCCE). His research interests include wireless communications, communication theory, signal processing, and RF propagation.

E-mail: fasandoval@utpl.edu.ec

Department of Computer Science and Electronic

Universidad Técnica Particular de Loja

C/. Marcelino Champagnat S/N

1101608 Loja, Ecuador

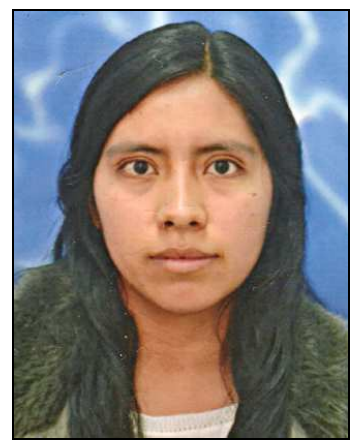

Betty Poma-Vélez is an Electronics and Telecommunications engineer at the Universidad Técnica Particular de Loja (2016). She is focusing on Networking and TIC enterprises. Her research interests focus around telecommunications, mainly radiofrequency propagation and wireless communications.

E-mail: bppoma@utpl.edu.ec

Department of Computer Science and Electronic

Universidad Técnica Particular de Loja

C/. Marcelino Champagnat S/N

1101608 Loja, Ecuador

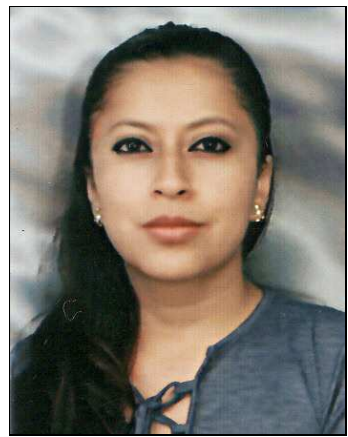

Alexandra Erreyes-Dota has been an Electronics and Telecommunications engineer at the Universidad Técnica Particular de Loja (UTPL) since 2016. She contributed research articles to the UTPL magazine in 2009 and 2010. Her research interests are: wave propagation in wireless telecommunications, wireless sensor networks, information management and communication technologies.

E-mail: ajerreyes1@utpl.edu.ec

Department of Computer Science and Electronic

Universidad Técnica Particular de Loja

C/. Marcelino Champagnat S/N

1101608 Loja, Ecuador 